Int. J. Electrochem. Sci., 13 (2018) $1120-1130$

International Journal of

ELECTROCHEMICAL

SCIENCE

www.electrochemsci.org

\title{
Influences of Fly Ash, Slag and Silica Fume on Electrochemical Chloride Removal Treatment with Simultaneous Migration of Silicate Ion
}

\author{
Hongyou Shan, Zhuyin Wang*, Jinxia Xu, Linhua Jiang, \\ College of Mechanics and Materials, Hohai University, Nanjing 210098, PR China \\ *E-mail: $\underline{\text { Tigerwang8810@126.com }}$
}

doi: $10.20964 / 2018.01 .58$

Received: 16 October 2017 / Accepted: 22 November 2017 / Published: 16 December 2017

The paper aims to investigate the effects of fly ash (FA), slag (SL) and silica fume (SF) on the electrochemical chloride removal treatment with simultaneous migration of silicate ion, which was to alienate the $\mathrm{Cl}^{-}$from the reinforcement and inject $\mathrm{SiO}_{3}{ }^{2-}$ into the mortar to interact with $\mathrm{Ca}(\mathrm{OH})_{2}$, respectively. The mortars (20\% and 30\% FA, 30\% and 50\% SL, $5 \%$ and $10 \%$ SF) contaminated by $2.0 \mathrm{wt} . \%$ chloride were prepared. The chloride extraction efficiency and corrosion properties of steel reinforcement in sodium chloride solution after the electrochemical treatment were measured to evaluate the effects. Results show that this electrochemical treatment is effective in extracting chloride from the mortar with various admixtures and prolong the initial time of corrosion for the steel in mortar with various admixtures. With the increase of FA content in mortar, the extracted chloride efficiency and the initial time of corrosion for rebar in mortar were increased. In contrast, with the increase of SL or SF content in mortar, the extracted chloride efficiency and the initial time of corrosion for rebar were decreased.

Keywords: electrochemical chloride removal; electrochemical measurement; corrosion.

\section{$\underline{\text { FULL TEXT }}$}

(C) 2018 The Authors. Published by ESG (www.electrochemsci.org). This article is an open access article distributed under the terms and conditions of the Creative Commons Attribution license (http://creativecommons.org/licenses/by/4.0/). 